\title{
Left atrial appendage occlusion in patients with atrial fibrillation: focus on current evidence and commercially available devices
}

\author{
Matteo Maurina ${ }^{1,2, \#}$, Alessandro Villaschi ${ }^{1,2, \#}$, Carlo Andrea Pivato ${ }^{1,2}$, Antonio Mangieri ${ }^{2}$, Mauro Chiarito ${ }^{1,2}$, \\ Letizia Bertoldi ${ }^{2}$, Martina Briani ${ }^{2}$, Fabio Fazzari ${ }^{2}$, Bernhard Reimers ${ }^{2}$, Damiano Regazzoli ${ }^{2}$, Paolo Pagnotta ${ }^{2}$ \\ 'Department of Biomedical Sciences, Humanitas University, Pieve Emanuele 20090, Milan, Italy. \\ ${ }^{2}$ IRCCS Humanitas Research Hospital, Rozzano 20089, Milan, Italy. \\ ${ }^{\#}$ Authors contributed equally and considered joint first authors.
}

Correspondence to: Dr. Damiano Regazzoli, Cardio Center, IRCCS Humanitas Research Hospital, Via Manzoni 56, Rozzano 20089, Milan, Italy. E-mail: damiano.regazzolilancini@humanitas.it

How to cite this article: Maurina M, Villaschi A, Pivato CA, Mangieri A, Chiarito M, Bertoldi L, Briani M, Fazzari F, Reimers B, Regazzoli D, Pagnotta P. Left atrial appendage occlusion in patients with atrial fibrillation: focus on current evidence and commercially available devices. Mini-invasive Surg 2021;5:53. https://dx.doi.org/10.20517/2574-1225.2021.88

Received: 18 Jul 2021 First Decision: 7 Sep 2021 Revised: 27 Sep 2021 Accepted: 8 Oct 2021 Published: 5 Nov 2021

Academic Editors: Andrea Scotti, Giulio Belli Copy Editor: Xi-Jun Chen Production Editor: Xi-Jun Chen

\begin{abstract}
Atrial fibrillation is the most common cardiac arrhythmia and is associated with morbidity and mortality due to cerebral or systemic embolization, with cardiac thrombi mainly forming in the left atrial appendage (LAA). Anticoagulation is the treatment of choice; however, in patients who do not tolerate anticoagulation, LAA occlusion (LAAO) is a valid alternative. Over the last decade, many different LAAO devices have been developed and tested in trials, providing good clinical results. The purpose of this paper is to make an overview of the current state of the art of LAAO procedure, with a focus on available devices and future perspectives.
\end{abstract}

Keywords: Left atrial appendage, left atrial appendage occlusion, atrial fibrillation, stroke prevention

\section{INTRODUCTION}

Atrial fibrillation (AF) is the most common cardiac arrhythmia and is associated with cerebral or systemic embolization as a result of possible thrombus formation in the left atrium and left atrial appendage $(\mathrm{LAA})^{[1]}$. In addition, AF is associated with increased mortality ${ }^{[2]}$. 
Anticoagulation has been shown to reduce the risk of embolization in $\mathrm{AF}^{[3,4]}$. However, in patients with high bleeding risk who are not candidates for anticoagulation, a different approach should be evaluated. Due to its anatomical characteristics and low-flow state predisposing to blood stasis and thrombosis, most atrial thrombi form in the LAA ${ }^{[5]}$. For this reason, percutaneous and surgical techniques have been developed over the years to exclude the LAA and prevent systemic embolization in AF. The purpose of this paper is to make an overview of the current state of LAAO procedure, with a focus on available devices and future perspectives.

\section{ASSESSING THE BLEEDING AND STROKE RISK IN AF}

The most feared complication of AF is systemic embolism, with ischemic stroke being the most clinically relevant and catastrophic event. While anticoagulant therapy is effective in reducing embolization, bleeding risk may equal or exceed embolic risk without anticoagulation in some patients ${ }^{[6]}$.

Therefore, clinicians are used to estimate ischemic and bleeding risk with different scores that are useful to choose the adequate management strategy. The CHA2DS2-VASc ${ }^{[7]}$ and HAS-BLED ${ }^{[8]}$ scores provide an estimate of the risk of stroke and bleeding events, respectively. Current guidelines (both European and American $)^{[9-11]}$ do not recommend antithrombotic treatment in patients with a CHA2DS2-VASc score $=0$ in males and $=1$ in females, while anticoagulation is indicated for higher scores. Regarding bleeding risk, modifiable risk factors in high-risk patients (HAS-BLED $\geq 3$ ) should be addressed and flagged up for regular follow-up with close INR monitoring or adjustment of the dose of anticoagulant medications, when possible. Of note, high scores should not be used as a reason to withhold oral anticoagulation (OAC) if a patient is considered eligible.

\section{INDICATION FOR LAAO}

For AF patients at high risk for ischemic stroke (CHA2DS2-VASc score $\geq 1$ in males and $\geq 2$ in females) who should receive anticoagulation but for whom OAC is contraindicated, both European and American guidelines give a IIb class recommendation for percutaneous LAAO to prevent systemic embolism ${ }^{[9,11]}$. Patients with the following characteristics may be included in this category:

- Prior severe bleeding (e.g., intracranial hemorrhage without a reversible cause).

- Diagnosed coagulation defect related to hemorrhage.

- History of recurrent bleedings (e.g., genitourinary or gastrointestinal) and anemia.

- Poor compliance or intolerance to OAC.

Furthermore, LAAO may also have a role in patients who refuse antithrombotic therapy due to personal preferences. While this population has not yet been extensively studied, future trials will focus on these patients, and indications for LAAO may considerably enlarge.

\section{Currently available devices}

Percutaneous LAAO devices are based on three different principles: the plug, the pacifier, and the ligation $^{[12]}$. While many different percutaneous devices are available in Europe, only two of them are currently FDA approved. In addition, surgical LAA exclusion can be performed via thoracoscopy with the AtriClip (FDA approved in 2010). The main characteristics of the current devices are summarized in Table 1. 
Table 1. Available left atrial appendage occlusion devices. Adapted and modified from the $2020 \mathrm{EHRA} / \mathrm{EAPCl}$ expert consensus statement update on catheter-based left atrial appendage occlusion $^{[12]}$

\begin{tabular}{|c|c|c|c|c|c|c|}
\hline Device name & Manufacturer & Principle & RCTs & Advantages & Potential disadvantages & Image \\
\hline WATCHMAN & Boston Scientific & Plug & $\begin{array}{l}\text { PROTECT-AF } \\
\text { PREVAIL }{ }^{[14]}{ }^{[13]}\end{array}$ & $\begin{array}{l}\text { Strong scientific evidence supporting its use ( } 2 \text { RCTs). Large } \\
\text { clinical experience due to widespread use }\end{array}$ & $\begin{array}{l}\text { May not be suitable for very short appendages due to its } \\
\text { design }\end{array}$ & \\
\hline $\begin{array}{l}\text { WATCHMAN } \\
\text { FLX }\end{array}$ & Boston Scientific & Plug & None & $\begin{array}{l}\text { Second iteration of WATCHMAN device. It fits in less deep } \\
\text { appendages and can be released more proximally }\end{array}$ & Relatively large (14 French) delivery system & \\
\hline WaveCrest & $\begin{array}{l}\text { Biosense } \\
\text { Webster }\end{array}$ & Plug & None & Can be used in short appendages & Little experience about its use & \\
\hline $\begin{array}{l}\text { Amplatzer } \\
\text { Cardiac Plug }\end{array}$ & Abbott Vascular & Pacifier & None & $\begin{array}{l}\text { Large registries documenting its use. Can be used in short } \\
\text { appendages (it is shorter than the WATCHMAN) }\end{array}$ & $\begin{array}{l}\text { First generation device. Less stable and higher rate of } \\
\text { incomplete closures than Amulet }\end{array}$ & \\
\hline Amulet & Abbott Vascular & Pacifier & AMULET-IDE ${ }^{[15]}$ & $\begin{array}{l}\text { Large registries and } 1 \mathrm{RCT} \text { about its use. More stable and larger } \\
\text { lobe than the ACP. Good for short LAAs (it is shorter than } \\
\text { WATCHMAN). Large clinical experience }\end{array}$ & $\begin{array}{l}\text { May not be the device of choice in very deep appendages } \\
\text { due to its design (larger than deep). Relatively large } \\
\text { (14 French) delivery system }\end{array}$ & \\
\hline Ultraseal & Cardia Inc. & Pacifier & None & $\begin{array}{l}\text { Disc and lobe are connected by a flexible joint allowing } \\
\text { orientation of the disc even in tortuous LAAs }\end{array}$ & $\begin{array}{l}\text { Sealing depends mostly on disc. Little experience about } \\
\text { its use }\end{array}$ & \\
\hline LAmbre & Lifetech & Pacifier & None & Can be implanted in very different LAA anatomies & $\begin{array}{l}\text { Sealing depends mostly on disc. Little experience about } \\
\text { its use }\end{array}$ & \\
\hline ATRICLIP & AtriCure & $\begin{array}{l}\text { Surgical } \\
\text { epicardial } \\
\text { exclusion }\end{array}$ & None & $\begin{array}{l}\text { No foreign material in contact with blood. Allows complete LAA } \\
\text { occlusion }\end{array}$ & Requires thoracoscopic access & \\
\hline
\end{tabular}

ACP: Amplatzer cardiac plug; RCT: randomized clinical trial; LAA: left atrial appendage.

\section{The plug principle}

Plugs are endovascular-delivered devices consisting of a lobe or umbrella that obstructs the neck of the LAA excluding it from the atrial cavity when it is completely endothelialized. The first CE-approved (CE-mark in 2005) device exploiting this principle is the WATCHMAN ${ }^{\mathrm{mi}}$ (Boston Scientific Corporation, 
Marlborough, MA). This device consists of a self-expandable nitinol cage covered by a membrane of polyethylene terephthalate (PTFE) [Figure 1] which is fully endothelialized by the heart tissue, resulting in permanent LAA sealing. The implant procedure is performed via the femoral vein with transesophageal echocardiography (TEE) or intracardiac echocardiography guidance, and its deployment requires a transseptal approach [Figure $1 \mathrm{C}$ ]. The second iteration of this device, WATCHMAN FLX, has been available since 2019 and may overcome some limitations of the first-generation occluders, with its higher suitability for shallower anatomies.

As of today, this device is the only LAAO device that has been prospectively compared with warfarin in two randomized controlled trials (PROTECT-AF and PREVAIL ${ }^{[1,144]}$ ) of AF patients without contraindication to OAC. The antithrombotic protocol of these studies consisted of a post-procedural 45-day period of warfarin anticoagulation, followed by a 6-month DAPT (aspirin and clopidogrel), which was followed by SAPT therapy (aspirin) indefinitely. Five-year outcomes of these two trials demonstrated that LAA occlusion provides stroke prevention in nonvalvular AF comparable to warfarin, with significant reductions in major bleedings and all-cause mortality $(\mathrm{HR}=0.48 ; P=0.0003 \text { and } \mathrm{HR}=0.73 ; P=0.035 \text {, respectively })^{[16]}$. Furthermore, the ASAP study showed that LAAO with the WATCHMAN ${ }^{\text {mo }}$ can be performed even in individuals with an absolute contraindication to $\mathrm{OAC}^{[17]}$. Given the solid scientific evidence, the WATCHMAN $^{\mathrm{m}}$ is a widely used device in daily clinical practice, and it was the first percutaneous device approved for LAA occlusion in the United States (FDA approval in 2015).

The principle of the plug is also exploited by the WaveCrest ${ }^{\bullet}$ (Biosense Webster, Irvine, CA), which obtained the CE mark in 2013 but is not FDA approved. This device may be useful in very short appendages as it is deployed more proximal, but it is less commonly used. A prospective, multicenter, randomized trial (NCT03302494) comparing this device and the WATCHMAN ${ }^{\mathrm{m}}$ is currently recruiting patients in the United States.

\section{The pacifier principle}

The "pacifier-like devices" are inspired by patent foramen ovale and atrial septal defect occluders, consisting of a lobe that is delivered into the LAA with an additional disc to seal the LAA ostium. As for the plug system, LAA exclusion relies on endothelialization of the device. The most widely used device is the Amplatzer $^{\text {Tw }}$ (Abbott Vascular, Chicago, IL; CE-approved in 2013). Although no randomized trial against anticoagulation has been conducted, both the first (Amplatzer Cardiac Plug) and the second (Amulet) generation of this device have shown their efficacy in reducing the risk of ischemic stroke and major bleeding compared to the predicted risk ${ }^{[18,19]}$. Compared to the Amplatzer Cardiac Plug, the newest Amulet has a deeper distal lobe with a more overriding proximal disc resulting in more complete LAA exclusion, especially for deeper LAAs [Figure 2A and B]. The recently published Amulet-IDE trial confirmed this finding, showing a higher LAA occlusion rate for the Amulet occluder compared with the WATCHMAN (98.9\% vs. 96.8\%; difference $=2.03 \%$; 95\% confidence interval (CI): 0.41-3.66; $P<0.001$ for noninferiority; $P$ $=0.003$ for superiority ${ }^{[15]}$. As for the WATCHMAN ${ }^{\mathrm{m}}$, Amulet deployment requires a transseptal approach during echocardiographic guidance. In August 2021, following the results of the Amulet-IDE trial, the Amplatzer $^{\text {m }}$ Amulet received FDA approval, becoming the second percutaneous LAAO device available in the United States.

Other Pacifiers are the LAmbre ${ }^{\mathrm{m} w}$ (Lifetech, China) and the Cardia Ultraseal ${ }^{\mathrm{m}}$ (Cardia Inc., St Paul, MN). The former consists of a fabric-enriched cover and an umbrella connected with a central waist ${ }^{[20]}$, while the Ultraseal $^{\text {mi }}$ is composed of a distal anchoring bulb and a proximal sail connected with an articulating joint that allows multidirectional movements and adjustments to different LAA shapes and ostium angles ${ }^{[21]}$. The 

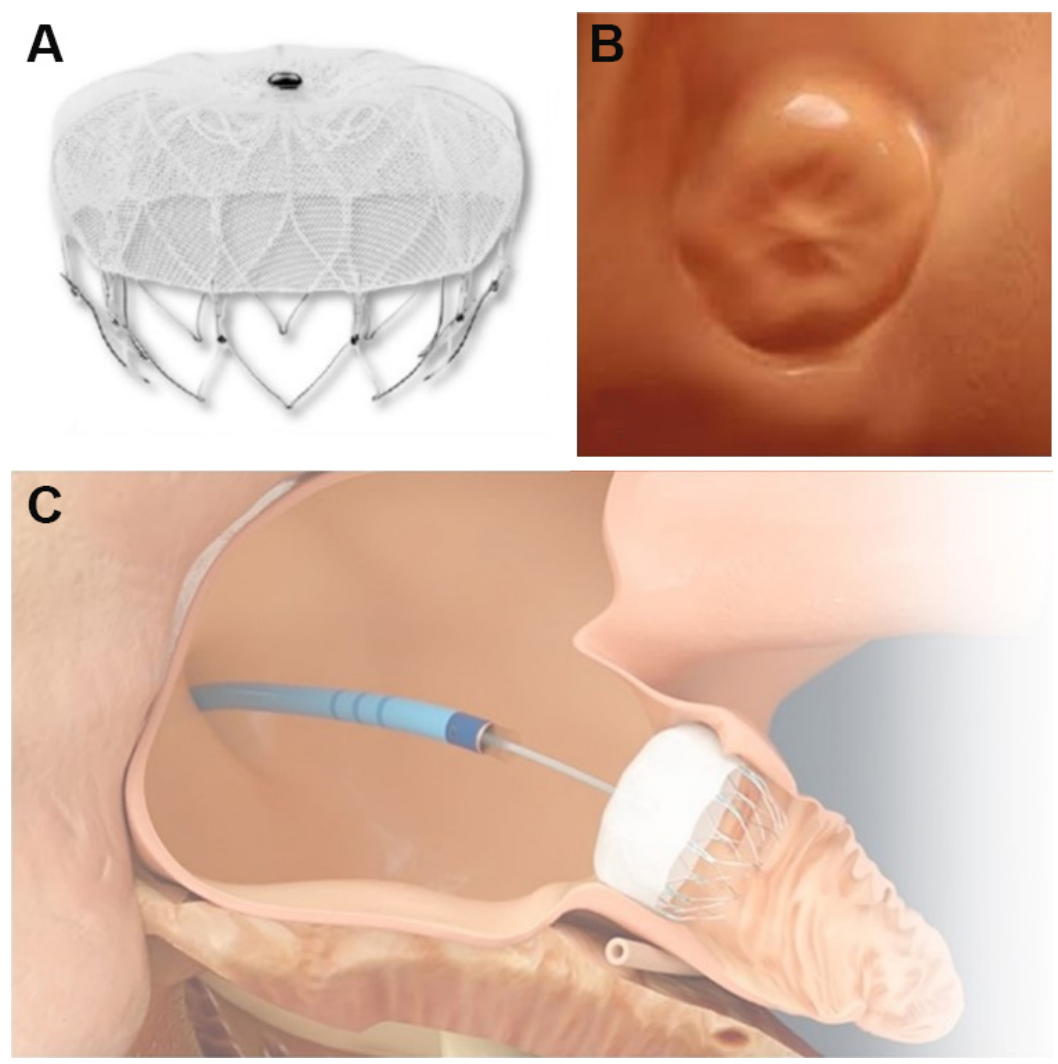

Figure 1. (A) The WATCHMAN and WATCHMAN FLX devices consist of a self-expandable nitinol cage covered by a membrane of polyethylene terephthalate (PTFE). (B) Heart tissue grows over the PTFE membrane guaranteeing device endothelialization and left atrial appendage (LAA) sealing. (C) The interatrial septum is crossed, and the device is released in the LAA.
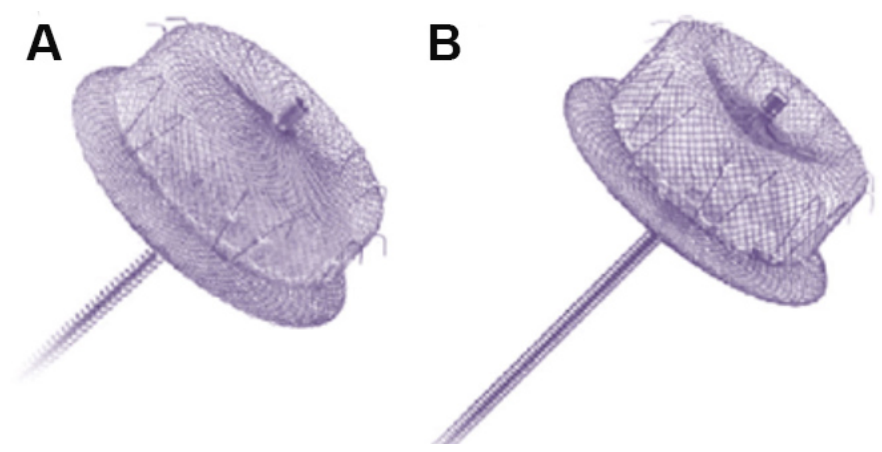

Figure 2. (A) First generation Amplatzer Cardiac Plug; and (B) second generation Amulet showing a deeper distal lobe with a larger proximal closure disc.

main advantage of these devices is that they possibly allow a complete closure of tortuous LAAs and of multilobulated appendages ${ }^{[22]}$. Although both devices received the CE mark in 2016, they are still not widely used in clinical practice ${ }^{[23]}$.

\section{The ligation principle}

LAA ligation simulates surgical closure and consists of snaring and ligating the body of the LAA with a double epicardial and endocardial approach. This principle is exploited by the LARIAT ${ }^{\mathrm{mm}}$ (SentreHEART, Pleasanton, CA; CE approved in 2015), which is a suture delivery device that is released around the LAA 
after both the epicardial and endocardial magnet-tipped guidewires have been connected together ${ }^{[24]}$. After initial encouraging results ${ }^{[24]}$, subsequent multicenter studies reported high periprocedural complications with high rates of serious pericardial effusions ${ }^{[25,26]}$, which led the FDA to announce safety issues in 2015 . For this reason, the use of the LARIAT ${ }^{\text {tu }}$ has been significantly reduced and this device is actually limited to rare cases of difficult anatomies, unsuitable for fully endovascular closure. Interestingly, every device, except the LARIAT $^{\mathrm{m} m}$, is made of nitinol, a mixture of nickel and titanium; therefore, device selection in patients severely allergic to nickel (e.g., extensive cutaneous reactions) is limited to the infrequently used ligation system, if deemed suitable by the operator.

\section{Thoracoscopic surgical closure}

A special consideration has to be made for epicardial LAA occlusion. As many patients develop recurrent AF after catheter ablation, may be unsuitable for the percutaneous procedure, or prefer a more durable intervention, thoracoscopic surgical AF ablation may be a valid alternative in patients with refractory and symptomatic $\mathrm{AF}^{[27]}$. In these cases, since LAA electrical isolation creates an akinetic and highly thrombogenic cul-de-sac ${ }^{[28]}$, concomitant thoracoscopic LAA clip closure may be indicated. The AtriClip ${ }^{\circ}$ (AtriCure, Inc. West Chester, PA, USA) is an FDA-approved device for epicardial LAA management. This device, consisting of a preloaded nitinol cap, is placed at the level of the epicardium at the base of the LAA, resulting in a complete LAA exclusion ${ }^{[28]}$. It has proven to reduce the incidence of stroke in AF patients undergoing heart surgery ${ }^{[29]}$. Moreover, the recent LAAOS III trial, which randomized AF patients undergoing cardiac surgery to concomitant LAA closure (some of which with AtriClip ${ }^{\circledR}$ ) or no closure, demonstrated a relative stroke risk reduction of $33 \%$ at 3.8 years, suggesting the potential benefit of this procedure ${ }^{[30]}$. However, up to date, these results can be applied only to AF patients undergoing cardiac surgery, while the potential benefit of this procedure in patients undergoing thoracoscopic AF ablation remains hypothetical, requiring further dedicated research.

\section{LAA imaging}

Before proceeding with LAA occlusion, imaging is fundamental to assess LAA anatomy and plan the procedure strategy. The main aspects to evaluate are the absence of LAA thrombosis and the LAA shape and size, to check for device compatibility. TEE and computed tomography angiography (CCTA) are the exams of choice. Even if CCTA may achieve high positive and negative predictive values and specificity, TEE is generally considered the gold standard in ruling out LAA thrombosis.

Thrombosis is visually confirmed with a careful evaluation of LAA body through different imaging planes, while LAA emptying velocity evaluation provides additional data about blood stasis. Low peak LAA emptying velocity $(<40 \mathrm{~cm} / \mathrm{s})$, in fact, may indicate a pro-thrombotic state and is a strong predictor of thrombus formation ${ }^{[31]}$. Moreover, TEE with $3 \mathrm{D}$ acquisitions plays a fundamental role in evaluating LAA anatomy and device compatibility, as it allows carefully analyzing the LAA without intravenous contrastmedium injection. Good quality 3D images (preferably at high framerate with multi-beat acquisition) may be post-processed to evaluate LAA depth, width, morphology, and orifice diameters. Furthermore, TEE images are useful to choose the most suitable occluder type, with specific measurements guiding the selection of the correct device size. In particular, the Amulet's size is determined measuring the LAA orifice and the device landing zone (10-12 mm inside the orifice) at different angles, while WATCHMAN requires measurements of the orifice diameter and LAA depth.

As mentioned above, CCTA with 3D multiplanar acquisitions is a valid alternative to TEE in preprocedural planning as it allows evaluating the LAA anatomy and provides a high level of device selection accuracy ${ }^{[32]}$. A small study even showed that LAA ostial perimeter measured on CCTA, compared to LAA TEE diameter, was associated with better prediction of the optimal device size ${ }^{[33]}$. However, it is less specific than 
TEE in detecting LAA thrombosis and can lead to misdiagnosis in the case of a "pseudo-thrombus" due to a delayed contrast flow into the LAA body. Moreover, it requires intravenous injection of nefrotoxic contrast medium.

Finally, image fusion is a very innovative technique that has gained popularity over the last years as an alternative to traditional imaging in guiding LAA occlusion procedures. This technology integrates the fluoroscopy into 3D CCTA and provides both real-time images regarding trans-septal puncture and device deployment and spatial information about the surrounding structures, which are difficult to assess with the 3D TEE alone. This technique, when performed by highly experienced operators, has been demonstrated to be even superior to standard TEE in terms of one-time successful deployment rate ${ }^{[34]}$. However, due to the higher cost compared to standard imaging, we believe that it could enter common clinical practice only in high-volume centers where LAAO is routinely performed.

\section{PERIPROCEDURAL COMPLICATIONS}

The most relevant and frequent periprocedural complications of LAAO are pericardial effusion and device embolization, while others such as stroke or access-site-related complications are relatively rare.

Pericardial effusion may be completely asymptomatic, or it may present as acute/subacute cardiac tamponade. It may be related to the transeptal puncture or the manipulation of catheters and the device against the thin-walled left atrium. Incidence of serious pericardial effusion ranges from $2.2 \%$ to $5 \%$, and pericardiocentesis has shown to be a safe and effective treatment for $\mathrm{it}^{[35]}$. It should be performed immediately in the case of hemodynamic instability, while, in the case of subacute or mild effusion, nonsteroidal anti-inflammatory drugs (e.g., aminosalicyclic acid or ibuprofen) are the treatment of choice.

Device embolization may happen early, during the procedure, or later, during follow-up. Embolization occurs in $<0.5 \%$ of patients ${ }^{[13]}$. Careful selection of the appropriate device and a correct deployment technique are the best way to avoid it. Percutaneous retrieval of the embolized device is the treatment of choice, if technically feasible, otherwise surgical retrieval may be required.

\section{MANAGEMENT OF ANTITHROMBOTIC THERAPY}

\section{Periprocedural antithrombotic therapy}

LAA closure is a percutaneous procedure, performed via transfemoral venous access. Anticoagulation with unfractionated heparin (UFH) is recommended during the procedure: it should be started prior to or immediately after transeptal puncture, at a dose of 70-100 IU/kg, aiming for an activated clotting time of $\geq$ $250 \mathrm{~ms}$. In patients with a contraindication to UFH, bivalirudin may be considered. Ideally, naive patients should receive a loading dose of acetylsalicylic acid (300-500 mg). Moreover, patients who are candidate to be discharged without oral anticoagulant therapy should be given an oral loading dose of clopidogrel (300$600 \mathrm{mg}$ ) prior to the procedure ${ }^{[12]}$.

\section{Antithrombotic therapy discharge}

The only available randomized clinical trials (RCTs) (PREVAIL and PROTECT-AF) did not include patients with contraindication to OAC. For this reason, the post-procedural management pursued in these studies consisted in a combination of warfarin (target INR 2-3) and aspirin $100 \mathrm{mg}$ for the first 45 days, followed by a first six-month DAPT period (aspirin and clopidogrel) and then by SAPT indefinitely. However, most patients undergoing percutaneous LAA closure have an absolute contraindication to OAC. In these cases, as endorsed by the recent EHRA/EACPI expert consensus statement ${ }^{[12]}$, a first six-month period of DAPT (aspirin and clopidogrel), followed by SAPT indefinitely is recommended. Although this 
protocol has been tested only for both the WATCHMAN ${ }^{\mathrm{m}[17]}$ and the Amulet ${ }^{[36]}$ devices, it is nowadays applied for all LAAO devices. A shorter DAPT duration (1-3 months) followed by SAPT may be considered in patients at high bleeding risk. In the case of prohibitive bleeding risk, shorter antithrombotic regimens, or even no therapy at all, may be considered, after careful evaluation.

After the first period (3-6 months or lower) of DAPT, SAPT is the treatment of choice for patients undergoing LAA percutaneous closure. There is no definite consensus whether SAPT should be carried on indefinitely: however, in accordance with Glikson et al. ${ }^{[12]}$, SAPT should be prescribed indefinitely or at least for the first year after the procedure. Aspirin is generally the drug of choice for long-term treatment, unless contraindicated.

\section{Antithrombotic therapy suboptimal or complicated LAA closure}

The most common complications after LAAO are device-related thrombosis (DRT) and incomplete occlusions. TEE is the most accurate way to check for both complications; however, it is not systemically performed after LAAO, especially when a good procedural result is obtained.

DRT has been a historically rare complication of percutaneous LAA closure, ranging from $<2 \%$ to $5 \%{ }^{\left[{ }^{[3]}\right.}$. However, according to data published more recently, DRT prevalence may complicate up to $38 \%$ of LAAO procedures ${ }^{[38]}$. DRT exhibits an increased risk of all-cause mortality and stroke: these patients' thromboembolic risk is estimated to be even higher than what would be expected by their baseline CHA2DS2-VASC score ${ }^{[39,40]}$. DRT may appear even months after LAAO and no strong correlation with ongoing antithrombotic treatment has been found ${ }^{[39]}$. Anticoagulation with subcutaneous heparin or OAC until thrombus dissolution is the treatment of choice for DRT ${ }^{[12]}$; however, it poses a significant dilemma in patients with an absolute contraindication to OAC. Sedaghat et al. ${ }^{[39]}$ recently demonstrated that DRT resolution may be achieved even with other antithrombotic therapies, but no strong evidence exists.

Incomplete occlusion of the LAA may be procedure related or may be secondary to delayed or incomplete endothelialization of the device. Despite being made of a deformable material such as nitinol, devices come in a finite number of sizes and usually with a circular shape: therefore, they may not adapt correctly to each LAA anatomy which typically exhibits an oval orifice. Small $(<5 \mathrm{~mm}$ at TEE evaluation), incomplete occlusions of the LAA are generally clinically irrelevant and may resolve spontaneously over time; therefore, OAC therapy would not be useful ${ }^{[41]}$. Moreover, even in larger incomplete LAA occlusions, OAC does not seem to be associated with stroke risk reduction ${ }^{[41]}$.

Therefore, regardless of complete LAA exclusion, no strong recommendation about adjunctive OAC after the procedure exists. However, four weeks of anticoagulation with low-molecular-weight heparin or VKA, if tolerated by the patient, followed by trans-esophageal echocardiogram reevaluation, appears to be a reasonable therapeutic approach in the case of incomplete LAA exclusion or thrombosis ${ }^{[42]}$.

\section{GAPS IN EVIDENCE AND FUTURE PERSPECTIVES}

The first and main gap in evidence is that initial randomized controlled trials comparing LAAO and anticoagulation showed good procedural results, and device performance emerged as non-inferior as compared to standard medical therapy in the overall population ${ }^{[13,14]}$. However, percutaneous LAA occlusion is still considered (in both guidelines and clinical practice) as an option for patients with absolute contraindication to oral anticoagulant therapy or for those with prohibitive bleeding risk. A tendency toward a more liberal use of the procedure was registered in real world practice, reinforcing doubts about the non-receipt of evidence in the guidelines. 
Second, one of the main gaps in evidence is that no trial randomizing patients to either LAAO or OAC exists. Therefore, LAAO does not have a Class I recommendation in current guidelines. The ASAP-TOO trial, randomizing patients unsuitable for OAC to receive either LAAO or APT, was interrupted for poor enrollment. This reflects the fact that LAAO is nowadays so popular and appears to be so safe that no clinician wants to risk randomization to the APT arm. Hence, registries are fundamental and represent the main source of data regarding LAAO procedures and different occlusion devices.

Then, additional evidence is needed to assess the safety and efficacy of LAA closure devices with respect to DOACs. In fact, DOACs proved to be at least as safe and effective as warfarin in preventing stroke in nonvalvular AF and are now widely used in this subset of patients. Initial data came from observational studies. Godino et al. ${ }^{[43]}$ showed comparable safety and efficacy between LAAO and DOACs in terms of thromboembolic and major bleeding events in patients with non-valvular AF at high bleeding risk, whereas another study found lower bleeding and mortality in LAAO rather than in DOAC patients ${ }^{[3]}$. A first, noninferiority RCT showed that LAAO was non-inferior to DOAC in preventing both ischemic and hemorrhagic complications in a high-risk cohort of AF patients ${ }^{[44]}$, but more robust data from larger studies are expected. The CLOSURE-AF (NCT03463317) is a prospective, RCT assessing the non-inferiority, and possibly superiority, of percutaneous closure of the LAA with respect to both ischemic and bleeding risk in high-risk patients vs. OAC (both DOACs and VKAs). It is going to be the largest trial ever conducted on this topic. Data are expected to be available in 2023.

Another debatable aspect is the type and duration of antithrombotic therapy after LAAO. The SAFE-LAAC (NCT03445949) trial is currently recruiting patients to evaluate the safety and efficacy of stopping DAPT after 30 days rather than at 6 months. Investigators are also going to evaluate potential differences in stopping all antithrombotic and antiplatelet agents six months after LAA occlusion $v s$. long-term treatment with single antiplatelet agent. The ANDES trial (NCT03568890) is also currently recruiting patients to compare DOAC vs. antiplatelet therapy for 8 weeks after percutaneous LAAO, for the prevention of DRT. Promising results about the efficacy of lower dose DOACs came from the phase IIb ADRIFT trial, showing lower thrombin generation after LAAO using rivaroxaban 10-15 mg daily rather than $\mathrm{DAPT}^{[45]}$, but new, larger trials are needed. The use of DOACs instead of antiplatelet agents in post-procedural antithrombotic therapy may seem counterintuitive: however, the lower bleeding risk of DOAC with respect to warfarin and the possibility of using reduced dosages might suggest a new role for anticoagulation in these patients. Moreover, in the light of the recent evidence coming from the LAAOS III trial ${ }^{[30]}$, LAAO could be considered an adjunctive therapy to anticoagulation to reduce ischemic risk, despite striking differences between surgical and percutaneous LAAO.

Other trials aim to perform head-to-head comparisons between LAAO devices analyzing safety, efficacy, and specific indications for different devices. The largest ongoing trial is the Amulet IDE trial which compares the Amplatzer device vs. the WATCHMAN ${ }^{\mathrm{m}}$ device and whose initial results have recently been published ${ }^{[15]}$. In total, 1878 participants have been enrolled worldwide and will be followed for 5 years after device implant, evaluating both stroke and bleeding risk, procedure-related complications, mortality, and device closure. The most relevant ongoing trials are summarized in Table 2.

Moreover, no definitive consensus on the appropriate echocardiographic follow-up to assess device success and complications has been published: whether a standardized approach might be useful in adapting current clinical practice still has to be determined. 
Table 2. On-going trials. Adapted and modified from the 2020 EHRA/EAPCl expert consensus statement update on catheter-based left atrial appendage occlusion ${ }^{[12]}$

\begin{tabular}{|c|c|c|c|c|c|c|c|}
\hline Trial name & Summary & Device & Intervention & $\begin{array}{l}\text { Patients } \\
\text { enrolled }\end{array}$ & Primary outcome(s) & Status & $\begin{array}{l}\text { Estimated primary } \\
\text { and study } \\
\text { completion date }\end{array}$ \\
\hline ANDES & $\begin{array}{l}8 \text { weeks OAC vs. APT for the } \\
\text { prevention of DRT }\end{array}$ & Not specified & DOAC vs. clopidogrel + aspirin & 350 & 2-month DRT & Recruiting & $\begin{array}{l}\text { September } 2022 \text { to } \\
\text { September } 2025\end{array}$ \\
\hline ASAP-TOO & $\begin{array}{l}\text { WATCHMAN vs. SAPT/no } \\
\text { treatment in NVAF patients with a } \\
\text { contraindication to OAC }\end{array}$ & WATCHMAN & LAAO + ATT vs. unspecified APT & 482 & $\begin{array}{l}\text { 7-day device/procedural safety and time to first } \\
\text { event of SSE }\end{array}$ & $\begin{array}{l}\text { Active, not } \\
\text { recruiting }\end{array}$ & $\begin{array}{l}\text { December } 2025 \text { to } \\
\text { December } 2025\end{array}$ \\
\hline $\begin{array}{l}\text { STROKE- } \\
\text { CLOSE }\end{array}$ & $\begin{array}{l}\text { LAAO vs. medical therapy for } \\
\text { stroke prevention in NVAF after } \\
\text { intracranial hemorrhage }\end{array}$ & Amulet & $\begin{array}{l}\text { LAAO }+45 \text { days of DAPT }+\geq 6 \\
\text { months of SAPT vs. OAC, DOAC, } \\
\text { SAPT, DAPT, no therapy }\end{array}$ & 750 & $\begin{array}{l}\text { Composite of SSE bleeding and all-cause } \\
\text { mortality up to } 5 \text { years }\end{array}$ & Recruiting & $\begin{array}{l}\text { May } 2022 \text { to May } \\
2030\end{array}$ \\
\hline SAFE-LAAC & $\begin{array}{l}\text { Short vs. extended post- } \\
\text { implantation DAPT and } 6 \text { months } \\
\text { of APT vs. long-term SAPT }\end{array}$ & Amulet & $\begin{array}{l}\text { (1) } 30 \text { days vs. } 6 \text { months of DAPT } \\
\text { (randomized) } \\
\text { (2) } 6 \text { months of APT vs. longer SAPT } \\
\text { (not randomized) }\end{array}$ & 160 & $\begin{array}{l}\text { Composite of SSE, TIA, non-fatal MI, CV, and } \\
\text { all-cause mortality, moderate-severe bleeding, } \\
\text { and LAA thrombosis }\end{array}$ & Recruiting & $\begin{array}{l}\text { January } 2021 \text { to } \\
\text { January } 2022\end{array}$ \\
\hline CLOSURE-AF & $\begin{array}{l}\text { LAAO vs. (D)OAC for stroke } \\
\text { prevention in NVAF }\end{array}$ & $\begin{array}{l}\text { CE-mark approved } \\
\text { LAAO devices }\end{array}$ & LAOO + APT vs. (D)OAC & 1512 & $\begin{array}{l}\text { Survival time free of SSE, major bleeding, and } \\
\text { CV or unexplained death }\end{array}$ & Recruiting & $\begin{array}{l}\text { February } 2021 \text { to } \\
\text { February } 2023\end{array}$ \\
\hline Occlusion-AF & $\begin{array}{l}\text { LAAO vs. DOAC for stroke } \\
\text { prevention in NVAF }\end{array}$ & $\begin{array}{l}\text { Amulet or } \\
\text { WATCHMAN }\end{array}$ & LAAO vs. DOAC & 750 & $\begin{array}{l}\text { Composite of SSE major bleeding and all-cause } \\
\text { mortality up to } 5 \text { years }\end{array}$ & Recruiting & $\begin{array}{l}\text { February } 2024 \text { to } \\
\text { October } 2030\end{array}$ \\
\hline SWISS-APERO & Amulet vs. WATCHMAN FLX & $\begin{array}{l}\text { Amulet or } \\
\text { WATCHMAN FLX }\end{array}$ & $\begin{array}{l}\text { AMPLATZER Amulet vs. } \\
\text { WATCHMAN/FLX }\end{array}$ & 200 & $\begin{array}{l}\text { Composite of LAA patency at } 45 \text { days and the } \\
\text { crossover from one device to the other during } \\
\text { device implantation }\end{array}$ & $\begin{array}{l}\text { Active, not } \\
\text { recruiting }\end{array}$ & July 2021 to May 2026 \\
\hline $\begin{array}{l}\text { WATCH- } \\
\text { TAVR }\end{array}$ & $\begin{array}{l}\text { Medical therapy vs. WATCHMAN } \\
\text { in patients with NVAF undergoing } \\
\text { TAVR }\end{array}$ & WATCHMAN & $\begin{array}{l}\text { TAVR + medical therapy vs. TAVR + } \\
\text { WATCHMAN }\end{array}$ & 350 & $\begin{array}{l}\text { Composite of all-cause mortality, stroke, and } \\
\text { bleeding }\end{array}$ & $\begin{array}{l}\text { Active, not } \\
\text { recruiting }\end{array}$ & $\begin{array}{l}\text { November } 2022 \text { to } \\
\text { November } 2022\end{array}$ \\
\hline $\begin{array}{l}\text { TAVI/LAA } \\
\text { occlusion }\end{array}$ & $\begin{array}{l}\text { Medical therapy vs. LAAO in } \\
\text { patients with NVAF undergoing } \\
\text { TAVR }\end{array}$ & Not specified & $\begin{array}{l}\text { TAVR + medical therapy vs. TAVR + } \\
\text { LAAO }\end{array}$ & 80 & $\begin{array}{l}\text { Embolic events, major bleeding, and CV } \\
\text { mortality }\end{array}$ & $\begin{array}{l}\text { Active, not } \\
\text { recruiting }\end{array}$ & $\begin{array}{l}\text { May } 2023 \text { to May } \\
2023\end{array}$ \\
\hline $\begin{array}{l}\text { CHAMPION- } \\
\text { AF }\end{array}$ & $\begin{array}{l}\text { WATCHMAN FLX as an } \\
\text { alternative to DOAC }\end{array}$ & WATCHMAN FLX & WATCHMAN vs. DOAC & 3000 & $\begin{array}{l}\text { Non-inferiority for SSE and CV death at } 36 \\
\text { months, non-inferiority for SSE at } 60 \text { months, } \\
\text { and superiority for non-procedural bleeding }\end{array}$ & Recruiting & $\begin{array}{l}\text { December } 2025 \text { to } \\
\text { December } 2027\end{array}$ \\
\hline
\end{tabular}

OAC: Oral anticoagulant; CV: cardiovascular; DOAC: direct OAC; DRT: device-related thrombosis; APT: antiplatelet therapy; SAPT: single APT; DAPT: double APT; ATT: antithrombotic therapy; LAAO: left atria appendage occlusion; MI: myocardial infarction; NVAF: non-valvular atrial fibrillation; SSE: stroke or systemic embolism; TAVR: transcatheter aortic valve replacement.

\section{CONCLUSION}

LAAO could be an alternative to anticoagulation in patients with non-valvular AF. While only two devices (WATCHMAN and AMULET) are both CE marked and FDA approved, other devices are commercially available in Europe, with high procedural success and a low rate of complications. 
However, some issues remain debatable such as appropriate duration of post procedural antithrombotic therapy, differences between devices, or complication management.

\section{DECLARATIONS}

\section{Authors' contributions}

Conception and drafting of the manuscript: Maurina M, Villaschi A, Pivato CA

Supervised and provided technical and material support: Mangieri A, Chiarito M, Regazzoli D, Fazzari F, Bertoldi L, Briani M

Revision of the manuscript for important intellectual content: Regazzoli D, Reimers B, Pagnotta P

\section{Availability of data and materials}

Not applicable.

\section{Financial support and sponsorship}

None.

\section{Conflicts of interest}

All authors declared that there are no conflicts of interest.

\section{Ethical approval and consent for participation}

Not applicable.

\section{Consent for publication}

Not applicable.

\section{Copyright}

(c) The Author(s) 2021.

\section{REFERENCES}

1. Pritchett EL. Management of atrial fibrillation. N Engl J Med 1992;326:1264-71. DOI PubMed

2. Corley SD, Epstein AE, DiMarco JP, et al; AFFIRM Investigators. Relationships between sinus rhythm, treatment, and survival in the Atrial Fibrillation Follow-Up Investigation of Rhythm Management (AFFIRM) Study. Circulation 2004;109:1509-13. DOI PubMed

3. Nielsen-Kudsk JE, Korsholm K, Damgaard D, et al. Clinical outcomes associated with left atrial appendage occlusion versus direct oral anticoagulation in atrial fibrillation. JACC Cardiovasc Interv 2021;14:69-78. DOI PubMed

4. Ezekowitz MD, Bridgers SL, James KE, et al. Warfarin in the prevention of stroke associated with nonrheumatic atrial fibrillation. Veterans Affairs Stroke Prevention in Nonrheumatic Atrial Fibrillation Investigators. N Engl J Med 1992;327:1406-12. DOI PubMed

5. Blackshear JL, Odell JA. Appendage obliteration to reduce stroke in cardiac surgical patients with atrial fibrillation. Ann Thorac Surg 1996;61:755-9. DOI PubMed

6. Shoeb M, Fang MC. Assessing bleeding risk in patients taking anticoagulants. J Thromb Thrombolysis 2013;35:312-9. DOI PubMed PMC

7. Lip GY, Nieuwlaat R, Pisters R, Lane DA, Crijns HJ. Refining clinical risk stratification for predicting stroke and thromboembolism in atrial fibrillation using a novel risk factor-based approach: the euro heart survey on atrial fibrillation. Chest 2010;137:263-72. DOI PubMed

8. Pisters R, Lane DA, Nieuwlaat R, de Vos CB, Crijns HJ, Lip GY. A novel user-friendly score (HAS-BLED) to assess 1-year risk of major bleeding in patients with atrial fibrillation: the Euro Heart Survey. Chest 2010;138:1093-100. DOI PubMed

9. Hindricks G, Potpara T, Dagres N, et al; ESC Scientific Document Group. 2020 ESC Guidelines for the diagnosis and management of atrial fibrillation developed in collaboration with the European Association for Cardio-Thoracic Surgery (EACTS): the Task Force for the diagnosis and management of atrial fibrillation of the European Society of Cardiology (ESC) Developed with the special contribution of the European Heart Rhythm Association (EHRA) of the ESC. Eur Heart J 2021;42:373-498. DOI PubMed

10. January CT, Wann LS, Alpert JS, et al; American College of Cardiology/American Heart Association Task Force on Practice Guidelines. 2014 AHA/ACC/HRS guideline for the management of patients with atrial fibrillation: a report of the American College of Cardiology/American Heart Association Task Force on Practice Guidelines and the Heart Rhythm Society. J Am Coll Cardiol 2014;64:e1-76. DOI PubMed

11. January CT, Wann LS, Calkins H, et al. 2019 AHA/ACC/HRS focused update of the 2014 AHA/ACC/HRS Guideline for the 
management of patients with atrial fibrillation: a report of the American College of Cardiology/American Heart Association Task Force on Clinical Practice Guidelines and the Heart Rhythm Society. J Am Coll Cardiol 2019;74:104-32. DOI PubMed

12. Glikson M, Wolff R, Hindricks G, et al. EHRA/EAPCI expert consensus statement on catheter-based left atrial appendage occlusion an update. EuroIntervention 2020;15:1133-80. DOI PubMed

13. Holmes DR, Reddy VY, Turi ZG, et al. Percutaneous closure of the left atrial appendage versus warfarin therapy for prevention of stroke in patients with atrial fibrillation: a randomised non-inferiority trial. Lancet 2009;374:534-42. DOI PubMed

14. Holmes DR Jr, Kar S, Price MJ, et al. Prospective randomized evaluation of the Watchman Left Atrial Appendage Closure device in patients with atrial fibrillation versus long-term warfarin therapy: the PREVAIL trial. J Am Coll Cardiol 2014;64:1-12. DOI PubMed

15. Lakkireddy D, Thaler D, Ellis CR, et al; Amulet IDE Investigators. Amplatzer ${ }^{\mathrm{TM}}$ Amulet ${ }^{\mathrm{TM}}$ left atrial appendage occluder versus watchman ${ }^{\mathrm{TM}}$ device for stroke prophylaxis (Amulet IDE): a randomized controlled trial. Circulation 2021. DOI PubMed

16. Reddy VY, Doshi SK, Kar S, et al; PREVAIL and PROTECT AF Investigators. 5-year outcomes after left atrial appendage closure: from the PREVAIL and PROTECT AF trials. J Am Coll Cardiol 2017;70:2964-75. DOI PubMed

17. Reddy VY, Möbius-Winkler S, Miller MA, et al. Left atrial appendage closure with the Watchman device in patients with a contraindication for oral anticoagulation: the ASAP study (ASA Plavix feasibility study with Watchman left atrial appendage closure technology). J Am Coll Cardiol 2013;61:2551-6. DOI PubMed

18. Tzikas A, Shakir S, Gafoor S, et al. Left atrial appendage occlusion for stroke prevention in atrial fibrillation: multicentre experience with the AMPLATZER Cardiac Plug. EuroIntervention 2016;11:1170-9. DOI PubMed

19. Hildick-Smith D, Landmesser U, Camm AJ, et al. Left atrial appendage occlusion with the Amplatzer ${ }^{\mathrm{TM}}$ Amulet ${ }^{\mathrm{TM}}$ device: full results of the prospective global observational study. Eur Heart J 2020;41:2894-901. DOI PubMed PMC

20. Huang H, Liu Y, Xu Y, et al. Percutaneous left atrial appendage closure with the LAmbre device for stroke prevention in atrial fibrillation: a prospective, multicenter clinical study. JACC Cardiovasc Interv 2017;10:2188-94. DOI PubMed

21. Pagnotta PA, Chiarito M, Pllaha E, et al. Left atrial appendage closure with the Ultraseal device: initial experience and mid-term follow-up. J Interv Cardiol 2018;31:932-8. DOI PubMed

22. Sabiniewicz R, Hiczkiewicz J, Wańczura P, Stecko W, Curzytek A. First-in-human experience with the Cardia Ultraseal left atrial appendage closure device: the feasibility study. Cardiol J 2016;23:652-4. DOI PubMed

23. Briosa E Gala A, Pope MTB, Monteiro C, et al. Long-term outcomes and periprocedural safety and efficacy of percutaneous left atrial appendage closure in a United Kingdom tertiary center: an 11-year experience. Heart Rhythm 2021;18:1724-32. DOI PubMed

24. Bartus K, Han FT, Bednarek J, et al. Percutaneous left atrial appendage suture ligation using the LARIAT device in patients with atrial fibrillation: initial clinical experience. J Am Coll Cardiol 2013;62:108-18. DOI PubMed

25. Miller MA, Gangireddy SR, Doshi SK, et al. Multicenter study on acute and long-term safety and efficacy of percutaneous left atrial appendage closure using an epicardial suture snaring device. Heart Rhythm 2014;11:1853-9. DOI PubMed

26. Price MJ, Gibson DN, Yakubov SJ, et al. Early safety and efficacy of percutaneous left atrial appendage suture ligation: results from the U.S. transcatheter LAA ligation consortium. J Am Coll Cardiol 2014;64:565-72. DOI PubMed PMC

27. Vos LM, Kotecha D, Geuzebroek GSC, et al. Totally thoracoscopic ablation for atrial fibrillation: a systematic safety analysis. Europace 2018;20:1790-7. DOI PubMed PMC

28. Di Biase L, Burkhardt JD, Mohanty P, et al. Left atrial appendage isolation in patients with longstanding persistent AF undergoing catheter ablation: BELIEF trial. J Am Coll Cardiol 2016;68:1929-40. DOI PubMed

29. Caliskan E, Sahin A, Yilmaz M, et al. Epicardial left atrial appendage AtriClip occlusion reduces the incidence of stroke in patients with atrial fibrillation undergoing cardiac surgery. Europace 2018;20:e105-14. DOI PubMed

30. Whitlock RP, Belley-Cote EP, Paparella D, et al; LAAOS III Investigators. Left atrial appendage occlusion during cardiac surgery to prevent stroke. N Engl J Med 2021;384:2081-91. DOI PubMed

31. Handke M, Harloff A, Hetzel A, Olschewski M, Bode C, Geibel A. Left atrial appendage flow velocity as a quantitative surrogate parameter for thromboembolic risk: determinants and relationship to spontaneous echocontrast and thrombus formation--a transesophageal echocardiographic study in 500 patients with cerebral ischemia. J Am Soc Echocardiogr 2005;18:1366-72. DOI PubMed

32. Wang DD, Eng M, Kupsky D, et al. Application of 3-dimensional computed tomographic image guidance to WATCHMAN implantation and impact on early operator learning curve: single-center experience. JACC Cardiovasc Interv 2016;9:2329-40. DOI PubMed

33. Goitein O, Fink N, Hay I, et al. Cardiac CT angiography (CCTA) predicts left atrial appendage occluder device size and procedure outcome. Int J Cardiovasc Imaging 2017;33:739-47. DOI PubMed

34. Mo BF, Wan Y, Alimu A, et al. Image fusion of integrating fluoroscopy into 3D computed tomography in guidance of left atrial appendage closure. Eur Heart J Cardiovasc Imaging 2021;22:92-101. DOI PubMed

35. Reddy VY, Holmes D, Doshi SK, Neuzil P, Kar S. Safety of percutaneous left atrial appendage closure: results from the Watchman Left Atrial Appendage System for Embolic Protection in Patients with AF (PROTECT AF) clinical trial and the Continued Access Registry. Circulation 2011;123:417-24. DOI PubMed

36. Landmesser U, Tondo C, Camm J, et al. Left atrial appendage occlusion with the AMPLATZER Amulet device: one-year follow-up from the prospective global Amulet observational registry. EuroIntervention 2018;14:e590-7. DOI PubMed

37. Aminian A, Schmidt B, Mazzone P, et al. Incidence, characterization, and clinical impact of device-related thrombus following left atrial appendage occlusion in the prospective global AMPLATZER Amulet observational study. JACC Cardiovasc Interv 2019;12:1003-14. DOI PubMed

38. Simard T, Jung RG, Lehenbauer K, et al. Predictors of device-related thrombus following percutaneous left atrial appendage occlusion. 
J Am Coll Cardiol 2021;78:297-313. DOI PubMed

39. Sedaghat A, Vij V, Al-Kassou B, et al. Device-related thrombus after left atrial appendage closure: data on thrombus characteristics, treatment strategies, and clinical outcomes from the EUROC-DRT-registry. Circ Cardiovasc Interv 2021;14:e010195. DOI PubMed

40. Sedaghat A, Nickenig G, Schrickel JW, et al; EWOLUTION study group. Incidence, predictors and outcomes of device-related thrombus after left atrial appendage closure with the WATCHMAN device-Insights from the EWOLUTION real world registry. Catheter Cardiovasc Interv 2021;97:E1019-24. DOI PubMed

41. Viles-Gonzalez JF, Kar S, Douglas P, et al. The clinical impact of incomplete left atrial appendage closure with the Watchman Device in patients with atrial fibrillation: a PROTECT AF (Percutaneous closure of the left atrial appendage versus warfarin therapy for prevention of stroke in patients with atrial fibrillation) substudy. J Am Coll Cardiol 2012;59:923-9. DOI PubMed

42. Lempereur M, Aminian A, Freixa X, et al. Device-associated thrombus formation after left atrial appendage occlusion: a systematic review of events reported with the Watchman, the Amplatzer Cardiac Plug and the Amulet. Catheter Cardiovasc Interv 2017;90:E11121. DOI PubMed

43. Godino C, Melillo F, Bellini B, et al. Percutaneous left atrial appendage closure versus non-vitamin K oral anticoagulants in patients with non-valvular atrial fibrillation and high bleeding risk. EuroIntervention 2020;15:1548-54. DOI PubMed

44. Osmancik P, Herman D, Neuzil P, et al; PRAGUE-17 Trial Investigators. Left atrial appendage closure versus direct oral anticoagulants in high-risk patients with atrial fibrillation. J Am Coll Cardiol 2020;75:3122-35. DOI PubMed

45. Duthoit G, Silvain J, Marijon E, et al. Reduced rivaroxaban dose versus dual antiplatelet therapy after left atrial appendage closure: ADRIFT a randomized pilot study. Circ Cardiovasc Interv 2020;13:e008481. DOI PubMed 